\title{
STEPHEN BILLETT
}

\section{1: EMERGING PERSPECTIVES ON WORKPLACE LEARNING}

\begin{abstract}
This introductory chapter discusses the development of considerations about learning through work and perspectives of workplace learning that are currently emerging through research internationally. A key purpose here is to map recent developments in thinking about learning through and for work. When one also considers individuals' needs to be learners as workers as they seek to secure continuity and development within their working life and social world, such perspectives help to inform how we might best organise, shape and appraise the character and processes of learning through and for work. This concern is never more important than when such learning is conceptualised simultaneously as processes of both social reproduction and transformation and of individual development and change. The chapter provides a bridge between existing contributions to our understanding about learning through work and the contributions offered in the following chapters. In doing so, it seeks to identify the strengths and the limitations of existing perspectives through theoretical and empirical work by focussing on the interdependent relations between the individual and social world in the processes of learning through and for work. Thus, it also foreshadows the analytic categories: (i) learning about self and agency; and (ii) learning about work tasks, that shape the structure of the book. In advancing these two bases as being particularly salient for elaborating understandings about learning for working life, the chapter first outlines the scope of the emerging interest in learning through work, as well as some of the purposes for and conceptions of learning through work. Next, procedural and conceptual developments that shape and reshape considerations of workplace learning are discussed. The chapter concludes by offering some parameters for workplace learning as a duality between what the workplace affords learners in terms of opportunities and support, and how individuals engage with these affordances as they learn through their experiences.
\end{abstract}

\section{EMERGING AND GROWING INTEREST IN WORKPLACE LEARNING}

There is growing interest in workplace learning as being broadly applicable to provisions of education across a range of educational sectors and practices. This interest seems set to continue as the securing of skills and the maintaining of 
workplace competence throughout working life become, globally, important priorities for governments, industry and workers (Organisation of Economic Cooperation and Development, 2000). Because of these priorities, there are growing demands for and interest in the provision of workplace experiences across a range of education sectors.

For instance, university programs in advanced industrial economies are increasingly emphasising occupational preparation in what is now being described as higher vocational education. Just as with the provision of vocational education in technical and vocational colleges, there are growing expectations that university students' educational preparation for professional work will include experiences in instances of their intended occupations. The aim is increasingly about securing a smooth transition into specific instances of professional work practice that they will engage with upon graduation. Consequently, experiences in workplaces are now becoming an increasingly common feature of higher education programs. There are also growing efforts to find ways of best integrating experiences across these two kinds of settings. School-organised workplace experiences have long been acknowledged as making important contributions to the preparation for working life and post-education transitions. Moreover, workplace learning experiences are used for a range of educational purposes. These include assisting individuals to identify the occupations that they prefer and to which they are suited, to experience and understand the world of work beyond educational institutions, and perhaps most commonly, to contribute to the development of occupational capacities (i.e. the conceptual, procedural and dispositional knowledge) required to participate in paid work.

In addition, increasingly (and in their own right), workplace learning experiences are seen to offer an effective means for maintaining skill currency across working lives (Raelin, 2007) as well as meeting specific enterprise skill needs, and maintaining the effectiveness of older workers (Tikkanen, Lahn, Ward, \& Lyng, 2002) and those who are otherwise marginalised and excluded from structured opportunities for skill development, such as those with disabilities (Church, Shragge, Fontan, \& Ng, 2007). Understanding how to best such needs can be realised through work and work-based learning may assist overcome some of the disadvantage. This includes providing learning experiences for workers from whom there are no course provisions to support their initial and ongoing occupational development. Thus, learning through workplace experiences offers the potential of realising important social, economic and personal purposes, including important equity outcomes-interests which are often tightly intertwined.

In these ways, workplaces as learning environments are moving from being seen as primarily providing experiences to support preparation for the trades and major professions (e.g. law, medicine, accountancy) to having a wider set of social, personal, equity and economic purposes. These include (i) developing and maintaining occupational competence for all kinds of workers across all kinds of occupational fields and hierarchies, and (ii) generating the skills required for enterprise-specific needs, as well as the economic imperatives of governments for having and sustaining competitive economies. Further, the social, personal, equity 
and economic purposes have now come to include: (i) assisting workers resist redundancy through maintaining their occupational competence; (ii) enhancing the kinds of learning experiences provided in educational institutions; (iii) supporting the effective transition for students from educational institutions into paid work activities; and (iv) being able to meet individuals' working life long needs through maintaining their skilfulness. It follows that such a salient set of purposes requires an equally comprehensive set of understandings about curriculum and pedagogic practices in order that they may be realised through workplace learning experiences.

Certainly, the growth of societal interest in learning through work has been paralleled by an expansion in the amount and fields of scholarship about learning through work-a scholarship which is providing helpful and increasingly nuanced conceptual and procedural accounts of adults' learning in and throughout working life. These developments serve to inform the pragmatic and strategic economic and social concerns about effective workforces, adequately skilled workers, competitive enterprises, and how workers can learn about new workplace requirements. They also serve the broader educational project through elaborating and advancing understandings about the process of human learning and development, in general, and how individuals' work life learning can be supported through activities and interactions in workplace settings. Certainly, adults' needs for conceptual and practical learning are often central to their personal subjectivity as well as to the place or practice in which they work. For these reasons, the concept of work life learning goes beyond the development of occupational capacities (i.e. competence), when defined narrowly. Instead, it incorporates the broader personal and dispositional qualities that are necessary requirements for the exercise of occupations by the individuals who are practising them (Billett, 2006b). Consequently, learning for work includes negotiations between its personal and social dimensions. It is through a consideration of these negotiations and individuals' conceptual and practical developments that bases for considering, organising, promoting and evaluating adults' learning through work can be best understood and advanced.

Without doubt, the legitimacy of learning through workplaces was boosted by the situated cognition movement of the late 1980s and early 1990s (Brown, Collins, \& Duguid, 1989; Collins, Brown, \& Newman, 1989). This movement emphasised the particular contributions to learning from the settings in which practice occurred and provided evidence that strategic as well as situationallyspecific learning can be realised through such experiences (Raizen, 1991). In addition, the value of situational contributions to learning and the prospects for the application of that knowledge to circumstances beyond those where it was learnt, rather than cognitive capacities alone, (Scribner, 1984) did much to support to the value of practice settings as sites for learning. Yet, the key motivation for the movement was towards improving the quality of learning experiences in educational institutions (Resnick, 1987), by understanding processes of transfer from one setting or activity to another. The need to enhance the transferability of school-learnt knowledge, even of general kinds (e.g. maths), was based on the 
realisation that such knowledge is not readily adaptable when applied to activities and circumstances that are different from the school-based activities through which they had originally been learnt (Raizen 1991). Therefore, considerations of situationally-distinct goals for practice and the authenticity of the contributions for learning through practice offered an explanation for the paucity of the transfer of learning from educational institutions to circumstances and practices beyond them (Newman, Griffin, \& Cole, 1984, 1989). The realisation that school-learnt knowledge did not necessarily transfer to other settings challenged the privileging of educational institutions as sites of learning. Indeed, research into the situated nature of learning often looked to workplaces as sites of authentic practices to see how learning arose through participation in work activities. However, and importantly, many of the more recent accounts of learning through work have moved beyond a concern to improve schooling and to legitimate workplaces as learning environments. Instead, they now focus on the pedagogic and curriculum potentials of workplace and work experiences, not just through a consideration of their physical and social settings, but also on those who engage in and learn through work.

Certainly, considerations of the worth of this kind of learning-conceptions of processes of learning through work and how these experiences might be organised to secure particular kinds of purposeful learning-are now warranted as important educational goals. Among the considerations are identifying what kinds of practices have demonstrated efficacy in supporting work life learning of particular kinds and the potential to guide workplace experiences towards particular desired learning outcomes. However, there are perennial issues about the worth and legitimacy of learning through work and in workplaces that need to be addressed and re-dressed. The societal sentiment about workplace learning is often ambiguous. Although there may be considerable acceptance of its worth and particular contributions, in an era that has come to accept mass and compulsory and ongoing education, workplace learning is often seen as inferior and subordinate to learning processes and outcomes that are provided by educational institutions. That is, rather than offering a different kind of (potentially rich) learning and affording particular kinds of experiences, workplaces are still often seen as being inferior (Billett, 2002). Therefore, there is often little effort given to granting workplace experiences the same kind of consideration and recognition as those afforded in educational institutions. Hence, there is still a need to provide bases for understanding and advancing workplaces as legitimate and worthwhile environments in which to learn.

It follows that although there is growing interest in practice-based contributions to learning, genuine efforts to integrate the two kinds of experiences in ways that acknowledge the particular contributions of each have been until now probably the exception. However, in many advanced industrial economies there are growing demands from students, the community and government for graduates to be able to move smoothly into professional practice and perform effectively in that practice. Therefore, as the desired educational outcome shifts from preparation for an occupation to the capacity to demonstrate professional competence upon 
graduation, the need to secure rich learning from the contributions of both settings means a greater focus on work-related learning and its effective integration in the higher education curriculum. Conversely, for those who are entering work or occupations were there is no available or accessible education provision, practicebased learning experiences become particularly important. For these learners, workplaces are the only source of learning experiences to develop the capacities for performing their work. In these ways, as the contributions of Allan, Lewis and Smith propose in their separate chapters, such experiences provide important opportunities for workers to learn about the techniques, practices and values of working life, and in particular specific occupations. These authors, respectively, refer to learning about farming, road transport and working in a restaurant, all of which required learning through practice. The authors emphasise the need to elaborate the distinct kinds of educational purposes to which learning is directed, and, therefore, the worth of particular kinds of workplace learning experiences in realising those purposes.

\section{PURPOSES OF LEARNING THROUGH WORKPLACES EXPERIENCES}

There are perhaps three key educational purposes for learning through work or through work practices. The first is to secure the contributions from authentic work or workplace experiences as part of an educational preparation for work and working life. As already noted, this includes assisting individuals to understand the requirements for working life and to identify the occupations in which they are interested and to which they are suited. For learners engaged in structured programs of occupational preparation in schools, universities and colleges, workplace experiences can be used to practice, apply, augment and extend learning secured in educational institutions. Moreover, the purposeful integration of experiences in the workplace can be used as a basis for the organisation of curriculum in educational institutions (Choy and Delahaye in this volume), or vice versa. For instance, it is possible to use students' reflections of work experiences in the classroom to assist their learning about the world of work, including a critical appraisal of its worth. This can be achieved by what Bailey, Hughes and Moore (2004) refer to as capturing and using the teachable moments that arise from students' discussions about their experiences in workplaces. This kind of pedagogic approach might also be used to realise other educational goals, such as informing about the transitions into work or across occupational practices, for older worker-learners.

Secondly, workplace learning experiences support the development of capacities (i.e. conceptual, procedural, dispositional) required to effectively engage in paid work, practice an occupation and to reach a high level of performance. Occupation preparation for both the professions and trades has long engaged students in extensive periods of occupational practice. Concerns about post-school pathways and transitions are also now leading schools to provide workplace experiences to assist students understand the world of work beyond schools. Moreover, as already noted, concerns about the transition from university and the applicability of what 
has been learnt there to professional practice is now motivating universities to engage their students in experiences in practice settings and in finding ways to integrate these experiences into their programs. Although long exercised in teacher, nurse and medical education, these kinds of experiences are now being extended across university programs preparing graduates for professional occupations-a trend that has been referred to as the growing field of higher vocational education. Again, this is not a particularly innovative step, as the co-op education movement of North America represents a long-standing response to this education concern (Van Gyn, 1996). However, these kinds of curriculum arrangements are often directed towards programs with applied purposes and for students with 'practical' rather than 'academic' interests and capacities. Hence (with the exception of medicine), they are often seen as being offered through less prestigious universities and programs,.

Thirdly, as foreshadowed, beyond initial preparation, there are growing imperatives for governments, employers and workers themselves to maintain skills throughout working life in order to resist redundancy, make effective work transitions as occupational requirements change and contribute to the workplace's continuity and development, and contribute to the economic prosperity of their communities. For instance, Vähäsantanen and Billett (this volume) note how educators find ways of negotiating significant changes to their professional practice. Their processes of learning for and through working life illustrate the kinds of negotiations that occur between social imperatives and personal contributions. Added to these are growing concerns about older workers and others who are marginalised (e.g. people with disabilities, non-native speakers) who often need to maintain their employment viability with limited assistance from their employers, and also a desire not to been seen as making demands upon co-workers. Thus, these workers engage in specific kinds of purposeful learning processes through negotiations with the workplace, and throughout work life.

Clearly, workplaces stand as distinct and legitimate learning environments in their own right and make particular contributions to educational programs and curriculum, and as sites for learning for individuals not engaged in educational programs. Yet, in order to fully utilise and perhaps improve the contributions of the workplace learning experiences, it is important to understand something of the worth of the contributions and processes of learning through work activity.

\section{PERSPECTIVES OF WORKPLACES AS LEARNING ENVIRONMENTS}

To understand more fully the qualities and potentials of workplaces and work practices as worthwhile environments in which to learn, it is necessary to capture their pedagogic qualities, that is, how learning arises through work. Certainly, there is a long held acceptance of the value of learning through practice and through workplace experiences. Plato describes the process of learning to become artisans and artists as that occurring through association, imitation and practice, starting with play, within the family of artists and artisans and in the circumstances of practice. As Lodge (Lodge, 1947) notes 
... at first, the imitation would be playful and childish, carried out with such toy tools as a child could handle. Later, it would become more deliberately purposive. Practice produced technical proficiency in detail and the growing boy would act first as his father's 'helper', then as his associate, and would eventually himself become the head of a family, and the centre from which further training in the family craft would radiate (p. 17).

Even before then, similar processes are described as being enacted in ancient Babylonia (Bennett, 1938). Subsequently, traditions of learning through practice for occupational purposes extended well into mediaeval times, buoyed by the practices and power of guilds (Deissinger, 2002). Most of the buildings, structures and artefacts from these times were the product of learning through work practice. The skills developed for constructing the most impressive and colossal of cathedrals across Europe progressed in ways similar to those described in ancient Babylon and Greece, through apprenticeship experiences and places of work and engagement that supported the construction of these buildings across generations of workers (Gimpel, 1961).

Indeed, long before education institutions were created for these purposes, hundreds of generations of skilled artisans across Europe, and elsewhere, learnt how to undertake skilled occupations solely through practice-based experiences. It was the impact of the decline of the guilds and the erosion of work based experiences in some European countries that created the need for specific educational institutions (Kieser, 1989). In addition, the shift from Latin as the language of science and knowledge enabled greater access to the knowledge needed for education and occupational practice. However, despite the growth of educational institutions for such purposes, the requirements for experience of practice have been sustained to this day in the trades and the professions, and periods of occupational practice are mandated as requirements to being credentialed as a practising tradesperson or professional. Indeed, these periods of practice are now being enacted more widely than ever across countries and educational sectors. Yet, despite all of this, there is often a parsimonious acknowledgement of the quality of learning processes and outcomes that arise through these practice-based experiences. Perhaps because of the legitimisation of learning processes and outcomes through (i) compulsory education and its massification at all levels of education, (ii) the status afforded written curriculum, and (iii) the role of trained teachers, learning experiences occurring outside of educational institutions are relegated to lower standing and worth (e.g. (Marsick \& Watkins, 1990)). Hence, workplaces are still often seen in terms of experiencing practice, rather than providing essential learning experiences in their own right. Yet, the evidence suggests that the potency of learning through such experiences is as great as that of learning within educational institutions, if the robustness of the learnt knowledge is the measure (Rogoff \& Lave, 1984). Further, there are consistent bases to understand the contributions of workplaces to learning occupational practice that arise from opportunities to learn through engagement in activities, being guided in that learning indirectly through observation as well as 
learning with the direct assistance by more experienced workers (Billett, 2001).Yet, even in programs for the trades and professions these experiences are still often seen primarily as a means to apply or practice what has been learnt in educational institutions. For instance, rarely are curriculum approaches or pedagogic measure enacted to draw upon and maximise the learning from apprentices' and professionals' experiences. That is, seldom are the workplace experience components of courses explicitly integrated into the curriculum or assessed in ways that are commensurate with their contributions to student learning.

Therefore, despite these traditions and newly emerging legitimisation of workplace learning experiences, their status still stands as being inferior, rather than different, to what is provided and experienced in educational institutions. A significant barrier is legitimising learning through practice in an era where strong associations between teaching and learning have become embedded through universal, compulsory and lengthy education; and in which teaching is seen as how important learning is best mediated. So, despite the fact that those who have learnt occupational practice invariably report the importance of learning through practice (Billett 2001), workplaces still lack the legitimacy, standing and credibility of certified learning through participation in educational institutions. This seems to be the case across all education sectors, including those whose purpose is to develop specific vocational knowledge. Indeed, institutions express concern that that their academic standing may be jeopardised through the inclusion of work-based experiences. Moreover, there are fears that some educational norms, such as a liberal and critical education are being threatened by such inclusions (Boud, Solomon, \& Symes, 2001). Furthermore, and not surprisingly, in the discourses of educational institutions and practice, teaching is privileged over learning. Therefore, as Marsick \& Watkins (1990) identified, the absence of written curriculum, qualified teachers and experiences purposely focused on individuals' learning may lead to workplace experiences as being seen as inevitably inferior.

However, many of these concerns and claims do not stand scrutiny. As studies from anthropology have found, robust (i.e. transferable) learning can arise as much through experiences outside of those organised and enacted in educational institutions, as in other settings (Rogoff \& Gauvain, 1984). Indeed, the anthropological literature provides helpful accounts of this kind of learning and evidence of its efficacy (Lave, 1990; Pelissier, 1991; Rogoff, 1990; Rogoff \& Lave, 1984). Experiences in educational institutions it seems are not necessarily better at developing these kinds of knowledge. More likely, it is the kinds and combinations of activities and interactions that are afforded learners and how they engage with them that are central to the development of knowledge, not where the experiences occur. These contributions then suggest a need to understand and appraise workplace learning through a consideration of both personal and social contributions to the processes and outcomes of that learning.

It seems that frameworks for understanding learning through work in contemporary times are well-served by a long tradition of learning through practice. These accounts also characterise workplaces as potent and legitimate 
environments for learning, not just for 'experiencing' and trialling and refining knowledge learnt elsewhere. They refer to contributions such as activities, interactions, artefacts and others as being pedagogic and purposive for learning, thereby offering frames for pedagogies and curriculum models for the workplace (e.g. Pelissier, Rogoff and Lave). Importantly, rather than didactic and school-like accounts of supporting learning, indirect forms of guidance and highly active roles for learners emerge as key qualities of such learning environments. The organisation of learning through activities and interactions, and the active process of observation and rehearsal stand as central elements of the workplace curriculum and pedagogic practices as identified in these accounts.

So, much of the 'first generation' of literature on workplaces has been directed at understanding how workplace experiences might improve learning experiences in educational institutions (i.e. schools, colleges and universities). However, building on these accounts, a second generation of research is now giving more attention to the particular attributes of sites and circumstances of practice (e.g. work and workplaces) as places to both participate in and learn. For instance, theoretical and procedural considerations of the pedagogic qualities of different kinds of work (Colin, 2004; Nerland \& Jensen, 2006), learning through errors (Bauer \& Mulder, 2007, and this volume), the active role of the learner (Billett, 2006b), their subjectivity and sense of self (Somerville \& Abrahamsson, 2003) and the complex entanglements between personal interests and capacities and those of the workplace (Fenwick, 2004) have arisen from quite different traditions to mainstream education. It is these perspectives that add new dimensions and scope to considerations of workplaces as learning environments.

\section{CONCEPTUAL AND PROCEDURAL ADVANCES}

The conceptual advances associated with learning through work are quite consistent with those informing the processes of learning more generally. Central amongst these are a greater emphasis on learning, instead of teaching, as is consistent with the growing acceptance of constructivism, and the acknowledgement of situational contributions, in ways analogous to social constructivism. The former indicates acceptance of an expansive and active role for learners, and positions them as being central mediators of what they experience and how and what they learn, thereby emphasising the personal epistemology of the learners. Here, central to individuals' participation, mediation and learning are their agency, capacities, and subjectivity. These concepts are central to explaining how individuals construe and construct their knowledge. The social constructivist movement acknowledges how the tasks, activities and settings in which learners participate afford particular kinds of contributions, which in terms of workplace learning can be understood as pedagogic qualities of work settings. Both of these [perspectives?] emphasise participation in work and learning as a dualistic conception comprising the contributions of social setting and the person. These advances are now discussed briefly in turn. 


\section{STEPHEN BILLETT}

\section{The exercise of self and agency of learners in learning through work}

The need for learners to be actively engaged in the process of learning anything of personal worth or requiring effort is widely accepted within many, and probably most, contemporary theories and concepts of learning. This includes how individuals construe, construct and interact with what they experience. These processes are particularly salient to considerations of learning through work and in workplaces. In provisions for learning offered through educational institutions, the teacher has a key mediating role in assisting the learner and guiding their development. However, whilst a range of guidance is available in work settings, including close guidance by more expert others (although usually on an intermittent basis), learners will necessarily mediate much of their own learning (Fuller \& Unwin, 2003). This is also likely to be essential where there is a need to integrate the contributions to that learning in both the educational and workplace setting, such as in apprenticeships and now increasingly for professional preparation and development (see Hanninen \& Etelapelto in this volume). In these circumstances, it is the learners who experience both kinds of settings and engage with others in learning and exercise efforts to maximise their learning through integrating the contributions of both kinds of experiences.

So, the interests, intentions and intentionalities of learners come to the fore here and their agency will shape the potential to realise rich outcomes through their experiences (see Cavanagh this volume). Moreover, the self and subjectivities will drive their learning in setting and securing rich learning outcomes, though not just through workplace learning experiences. A key basis for ongoing learning throughout working life will likely be what motivates, directs and focuses individuals' efforts at learning through work. For instance it seems for older workers, semi-skilled, those of colour or with a disability, personal agency will be central in managing their learning through work, as the evidence suggests these workers are those least likely to be afforded workplace support for their learning.

To this end, there needs to be a greater de-centering of the focus of learning through work from an emphasis on the physical and social contributions of the setting to accommodate the bases and means by which learners contribute to workplaces as learning environments. Helpful accounts of personal epistemologies and learner agency have been generated in recent work (Hodkinson \& Hodkinson, 2004). Many of these accounts emphasise the relations and negotiations between individual workers' and their workplaces' (i.e. the personal and the situated) contributions to learning workplace practices, techniques, norms etc. (see Smith this volume). This can include the kinds of distinct outcomes that arise through negotiations between individuals and particular kinds of work activities (see Virtanen, Tynjala \& Stenstrom this volume). Such accounts illuminate how individuals elect to respond to governmental imperatives and employer requests to learn continually throughout working life. For instance, these accounts advise governments and employers that their ambitions for citizens and employees' lifelong workplace learning are unlikely to be realised unless more consideration is given to the needs, interests and personal trajectories of those who are being 
exhorted to learn for national and workplace purposes. Consequently, conceptions of workplace learning need to include considerations of the salience of personal epistemologies and the need to develop these for learning throughout working life, and in ways consistent with accommodating individuals' occupational trajectories. This includes the process of participating in a particular occupational practice and negotiating the process of coming to identify and belonging to a particular occupation (see Allan this volume), and processes of reflection that serve to sustain and extend professional identity (see Gartmeier, Kipfmuller, Heid \& Gruber this volume). Yet, these epistemologies comprise more than personal strategies, they are central to and shaped by individuals' subjectivities and sense of self. This means that engaging learners' interest is a necessity and is central to efforts aligned with lifelong or work life learning.

\section{Pedagogic qualities of workplaces}

Beyond the personal, greater consideration needs to be given to how concepts of pedagogy, curriculum and epistemology can be used to helpfully inform processes of learning through work. Taking their pedagogic qualities as an instance, earlier, socially-orientated accounts of the contributions to learning of physical and social settings, such as communities of practice (Lave \& Wenger, 1991) and activity systems (Engestrom, 1993) advanced the pedagogic qualities of workplaces in terms of shared premises for participation and learning, and social system that shape participation and learning. However, more recent accounts of the social contributions to learning through work have provided more elaborated accounts of the pedagogic qualities and potential of workplace settings (Billett. 2001). Some of these detail the pedagogic qualities of particular kinds of work and workplaces, whilst others provide more detailed considerations of the artefacts and practices in workplaces that contribute to learning. This includes the kinds and qualities of interactions, such as experience sharing (see Collin \& Paloniemi this volume) and collaborations (see Hökkä, Rashu, Puttonen \& Eteläpelto this volume) that lead authors to highlight the epistemic qualities of the workplace. These kinds of perspectives are helpful as they finesse and refine the contributions of earlier accounts. They also permit more comprehensive and detailed accounts of how the contributions of workplace settings can work to shape learning and how these might best be exploited to achieve particular kinds of learning outcomes.

Moreover, as considerations of workplaces as learning environments have matured, the range of procedural responses has also grown. What is distinct about these provisions is that they centre on the provision of the workplace as a source of learning experiences in their own right and not just to augment or extend learning from other sources (i.e. educational programs). These include learning from work errors - how together qualities of workplace environments and workers' personal dispositions shape the prospect of learning purposively through workplace errors (Bauer \& Mulder, 2007), learning projects (Poell, 2006), critical reflections through work experiences (van Woerkom, 2003) guided learning in the workplace (Billett, 2001), expanding learning opportunities (Fuller \& Unwin, 2004), the 
development of a workplace curriculum (Billett, 2006a), the use of strategies to secure access to knowledge that would otherwise remain hidden from the workerlearners (see Lewis this volume), and means through which to foster transfer (see Festner \& Gruber this volume). In different ways, these kinds of approaches open up considerations for the means by which workplace pedagogies can be developed - key premises for framing workplace learning.

Yet, there are important conceptual and procedural goals still to be secured. For instance, much conceptual development is premised on learners being in socially rich circumstances that provide models, guidance, and so on. However, many workers are physically and socially isolated and therefore do not engage in or learn through these kinds of socially rich environments. Therefore, more needs to be known about learning in relatively socially impoverished environments. Contemporary and emerging occupational and workplace practice is such that workers may only be afforded access to particular kinds of workplace experiences, and possibly not those that are sufficient for the development of comprehensive workplace, let alone occupational, knowledge. So, understanding further how these kinds of knowledge can be developed is as an important goal. The need to learn symbolic forms of knowledge and those that are not opaque (Bresnahan, Brynjolsson, \& Hitt, 2002; Zuboff, 1988) or easy to learn, thereby requiring intentional pedagogic practices that can make this knowledge accessible and comprehensible is another goal. Moreover, a key concern about learning through practice is that uncritically accepting practices of the past and present may not assist learning requirements for the future. Also, considering how workplace learning opportunities are asymmetrically distributed on the basis of age, gender, language and educational achievement levels, more needs to be done to improve the equity of the affordances of opportunity. Hence, there has to be a critical and questioning stance when advancing considerations of learning through work. Frameworks supporting and extending learning through work need to constantly and critically examine (i) the kinds and processes of learning that arise through participation in work and (ii) how these forms of learning can be aligned with the array of purposes to which they are directed (e.g. rich occupational knowledge).

The contributions to this book engage with many of these ideas through their organisation into two sections that focus on the imperatives of the self and the workplace practice and are entitled: (i) learning about self and agency; and (ii) learning about work tasks. The contributions engage with and advance these key organising concepts and in ways that elaborate their significance to discussing learning through work life.

\section{WORKPLACE AS SITES FOR LEARNING}

In conclusion, ways of thinking about learning in workplaces (or pedagogies for the workplace) have commonalities with learning in other settings, albeit manifested in conceptions of epistemology, curriculum and pedagogy in ways that reflect the particular practices within comprise workplaces. These are premised on a set of practices to support learning that were in use well before those for 
schooling had been developed. Overall, the commonalities include considerations of what is provided by the setting to support learning (i.e. its affordances) and how individuals elect to engage with, participate and mediate in what is afforded them by the setting. These considerations are equally applicable for adults' learning across a range of social institutions (e.g. universities, colleges, communities and workplaces). In curriculum terms each of these has purposes (i.e. intentions for learning), enactments (e.g. means of supporting that learning), individuals who can support learning (e.g. teachers, co-workers) and learners (e.g. students, workers) that mediate how and what they learn through what they experience in the various settings. Yet, there are some distinctions in the particular kinds of experiences that workplaces and educational institutions afford, ways in which learners identify themselves and elect to participate in learning and for what purposes. The premises for workplace curriculum and pedagogy will be founded on practices being enacted in workplaces (the provisions of goods or services) as directed towards learning occupational knowledge as per the workplace's particular requirements. This may be distinct from the stated aim of educational institutions: intentional learning for an occupation. Also, the identity and bases for participation by workers, some of whom will be guiding the work and learning of others (e.g. more experienced workers), are likely to be distinct from those who see themselves as teachers and students in educational institutions, and feature a strongly agentic role for learners. Yet, these are largely minor distinctions, thereby holding that learning through work can be informed, legitimised and understood and appraised through orthodox curriculum concepts and pedagogic practices, and that there are also distinct features and characteristics that need to be accounted for in these frameworks.

So, in all, understanding and elaborating learning through work can be founded on the dualities of what the workplace affords to those employed within them and how those individuals elect to engage with what is afforded them. Learning through practice, through errors and by processes of observation and imitation, practice and the direct guidance of experienced co-workers all stand as key elements of that framework. Also, the kinds of work practices, and personal values and bases of identity shape these dualities and the relations between them. In addition, the purposes of learning and the desired outcomes of that learning also stand as important foundations for making judgements about the value of that learning ad how it might best be enhanced. These enhancements may well be realised through work activities or require particular and targeted intervention as perhaps increasingly components of work-related knowledge become inaccessible and need to be made explicit. The contributions of the sections here do much to advance these key concerns.

\section{REFERENCES}

Bailey, T. R., Hughes, K. L., \& Moore, D. T. (2004). Working knowledge: Work-based learning and educational reform. New York: RoutledgeFalmer.

Bauer, J., \& Mulder, R. H. (2007). Modelling learning from errors in daily work. . Learning in Health and Social Care( 6), 121-133. 


\section{STEPHEN BILLETT}

Bennett, C. A. (1938). The ancestry of vocational education. In E. A. Lee (Ed.), Objectives and Problems of Vocational Education (2nd ed., pp. 1-19). New York: McGraw-Hill Book Company.

Billett, S. (2001). Learning in the workplace: Strategies for effective practice. Sydney: Allen and Unwin.

Billett, S. (2002). Critiquing workplace learning discourses: Participation and continuity at work. Studies in the Education of Adults, 34(1), 56-67.

Billett, S. (2006a). Constituting the workplace curriculum. Journal of Curriculum Studies, 38(1), 31-48.

Billett, S. (2006b). Relational interdependence between social and individual agency in work and working life. Mind, Culture and Activity, 13(1), 53-69.

Boud, D., Solomon, N., \& Symes, C. (2001). New Practices for New Times. In D. Boud \& N. Solomon (Eds.), Work-based learning: A New Higher Education? (pp. 3-17). Buckingham: Open University Press.

Bresnahan, T. F., Brynjolsson, E., \& Hitt, L. (2002). Information technology, workplace organisation and the demand for labor: Firm-level evidence. Quarterly Journal of Economics, 117(1), 339-376.

Brown, J. S., Collins, A., \& Duguid, P. (1989). Situated Cognition and the Culture of Learning. Educational Researcher, 18(1), 32-34.

Church, K., Shragge, E., Fontan, J. M., \& Ng, R. (2007). While no one in watching: Learning in social action among people who are excluded from the labour market. In K. Church, N. Bascia \& E. Shragge (Eds.), Making Sense of Turbulent Times. Dordrecht: Springer.

Colin, K. (2004). Workplace's learning and life. International Journal of Lifelong Learning, 4(1), 24-38.

Collins, A., Brown, J. S., \& Newman, S. E. (1989). Cognitive apprenticeship: Teaching the crafts of reading, writing and mathematics. In L. B. Resnick (Ed.), Knowledge, Learning and Instruction, essays in honour of Robert Glaser (pp. 453-494). Hillsdale, N J: Erlbaum \& Associates.

Deissinger, T. (2002). Apprenticeship systems in England and Germany: decline and survival. Paper presented at the Towards a history of vocational education and training (VET) in Europe in a comparative perspective, Florence.

Engestrom, Y. (1993). Development studies of work as a testbench of activity theory: The case of primary care medical practice. In S. Chaiklin \& J. Lave (Eds.), Understanding Practice: perspectives on activity and context (pp. 64-103). Cambridge, U.K: Cambridge University Press.

Fenwick, T. (2004). Learning in portfoliowork: anchored innovation in and mobile identity. Studies in Continuing Education, 26(2), 229-246.

Fuller, A., \& Unwin, A. (2003). Fostering workplace learning:Looking through the lens of apprenticeships. European Educational Research Journal, 2(1), 41-55.

Fuller, A., \& Unwin, L. (2004). Expansive learning environments: Integrating organisational and personal development. In H. Rainbird, A. Fuller \& A. Munroe (Eds.), Workplace learning in context (pp. 126-144). London: Routledge.

Gimpel, J. (1961). The Cathedral Builders. New York: Grove Press.

Hodkinson, P. H., \& Hodkinson, H. (2004). The significance of individuals' dispositions in the workplace learning: a Case study of two teachers. Journal of Education and Work, 17(2), 167-182.

Kieser, A. (1989). Organizational, institutional, and societal evolution: medieval craft guilds and the genesis of formal organizations. Administrative Science Quarterly, 34(4), 540-564.

Lave, J. (1990). The culture of acquisition and the practice of understanding. In J. W. Stigler, R. A. Shweder \& G. Herdt (Eds.), Cultural psychology (pp. 259-286). Cambridge, UK: Cambridge University Press.

Lave, J., \& Wenger, E. (1991). Situated learning - legitimate peripheral participation. Cambridge, UK: Cambridge University Press.

Lodge, R. C. (1947). Plato's theory of education. London: Kegan Paul, Trench, Trubner.

Marsick, V. J., \& Watkins, K. (1990). Informal and incidental learning in the workplace. London: Routledge.

Nerland, M., \& Jensen, K. (2006). Insourcing the management of knowledge and occupational control: an analysis of computer engineers in Norway. International Journal of Lifelong Education, 26(3), 263-278. 
Newman, D., Griffin, P., \& Cole, M. (1984). Social constraints in laboratory and classroom task. In B. Rogoff \& J. Lave (Eds.), Everyday cognition: Its development in social context. Cambridge, Mass: Harvard University Press.

Newman, D., Griffin, P., \& Cole, M. (1989). The construction zone: Working for cognitive change in schools. Cambridge, UK: Cambridge University Press.

Organisation of Economic Cooperation and Development. (2000). Economics and Finance of Lifelong Learning. Paris: OECD.

Pelissier, C. (1991). The anthropology of teaching and learning. Annual Review of Anthropology, 20, 75-95.

Poell, R. (2006). Organising learning projects whilst improving work: Strategies for employees, managers and HRD specialists. In J. N. Streumer (Ed.), Work-related learning (pp. 71-94). Dordretch: Springer.

Raelin, J. A. (2007). Toward an Epistemology of Practice. Academy of Management Learning \& Education., 6(4), 495-519.

Raizen, S. A. (1991). Learning and work: The research base. Vocational Education and Training for youth: Towards coherent policy and practice. Paris: OECD.

Resnick, L. (1987). Learning in school and out. Educational Researcher, 16(9), 13-20.

Rogoff, B. (1990). Apprenticeship in thinking - cognitive development in social context. New York: Oxford University Press.

Rogoff, B., \& Gauvain, M. (1984). The cognitive consequences of specific experiences - weaving versus schooling among the Navajo. Journal of Cross-Cultural Psychology, 15(4), 453-475.

Rogoff, B., \& Lave, J. (Eds.). (1984). Everyday cognition: Its development in social context. Cambridge, Mass: Harvard University Press.

Scribner, S. (1984). Studying working intelligence. In B. Rogoff \& J. Lave (Eds.), Everyday cognition: Its development in social context (pp. 9-40). Cambridge, Mass: Harvard University Press.

Somerville, M., \& Abrahamsson, L. (2003). Trainers and learners Constructing a Community of Practice: Masculine Work Cultures and Learning Safety in the Mining Industry. Studies in the Education of Adults, 35(1), 19-34.

Tikkanen, T., Lahn, L., Ward, P., \& Lyng, K. (2002). Working life changes and training of older workers. Trondheim: Vox.

Van Gyn, G. H. (1996). Reflective Practice: The Needs of Professions and the Promise of Cooperative Education. Journal of Cooperative Education, 31(2-3), 103-131.

van Woerkom, M. (2003). Critical reflection at work. Enschede: Twente University.

Zuboff, S. (1988). In the age of the smart machine: The future of work and power. New York: Basic Books.

\section{AFFILIATIONS}

\section{Stephen Billett}

Faculty of Education

Griffith University

Australia 